\title{
Assessment of the level of noise and chemical air pollution in two distinct urban areas
}

https://doi.org/10.21698/rjeec.2020.216

Proceedings Paper

\begin{abstract}
MIHAI BRATU ${ }^{1}$, ELENA BUCUR ${ }^{1}$, VALERIU DANCIULESCU ${ }^{1}$, MIHAELA PETRESCU $^{1}$, GHEORGHITA TANASE ${ }^{1}$, OVIDIU VASILE ${ }^{2}$
\end{abstract}

\author{
${ }^{1}$ National Research and Development Institute for Industrial Ecology - ECOIND, 71-73 Drumul Podu Dambovitei, \\ sector 6, 060652, Bucharest, Romania \\ ${ }^{2}$ University Politehnica of Bucharest, Department of Mechanics, Splaiul Independentei 313, 060042, Bucharest, \\ Romania \\ *Corresponding author(e-mail): cmm_bratu@yahoo.com
}

\begin{abstract}
In the paper are presented the results of tests on the evaluation of the level of noise and chemical air pollution in two distinct urban areas: an industrial area and an area characterized by heavy road traffic, with a focus on the novelty elements introduced by the regulations in force on the measurement and management of the level of ambient and industrial noise by periodically developing specific noise maps. The results of direct tests and noise maps developed in the case of the studied areas indicated higher values of the indicators measured near the road artery compared to the other measuring points, highlighting the influence of vegetation in urban areas to reduce noise levels and reduce air pollution.
\end{abstract}

Keywords: noise level, noise map, pollutants, industrial area

\section{INTRODUCTION}

The environment is an essential element of human existence and is the result of the interference of natural elements with elements created by human activity. Ensuring a proper quality of the environment, protecting it as a necessity of survival and progress, is a matter of major interest and certain topicality [1]. Industrial development policy in recent years has aimed at transforming the industrial economy into an economy based on sustainable development interest in the protection of the environment in general and air in particular; special attention is paid to noise pollution in urban areas, due mainly to heavy road traffic and activities carried out in industrial areas [25].

Noise is a risk factor with harmful effects on the human body, which can lead to disorders not only of the hearing aid but also of other organs with effects on labor productivity but also on the general health of people [6-12].

At the European Union level the assessment and

$$
L_{\text {Aeq }, T}=10 * \lg \sum_{i=1} 10^{\left(L_{e q, T i}+A_{i}\right) / 10} \quad(\mathrm{~dB})
$$

where $A_{i}-$ represents the correction corresponding to the weighting on curve A according to the standard IEC 61672-1, $i$ frequency band index, $T-$ a corresponding management of ambient noise are regulated by Directive 2002/49/EC of the European Parliament and of the Council of 25 June 2002 on ambient noise assessment and management and Commission Directive (EU) 2015/996 OF 19 May 2015 laying down common noise assessment methods requiring the EU Member States to assess and manage ambient noise by regularly making strategic noise maps for road traffic noise sources and industrial activities as well as other types of noise. The two directives are taken up in the national legislation by Law $121 / 2019$ thus creating a single legislative framework on ambient noise assessment and management [13-15].

Based on method standards [16-18] the noise level is determined in the frequency range 31,5 $\mathrm{Hz}-8 \mathrm{kHz}$ in $1 / 3$ octave bands. For noise produced by road and industrial traffic, the average sound pressure level weighted on the weighting curve $\mathrm{A}$ is calculated according to the equation:

period.

All input values affecting the emission level of a source shall be determined at least with the accuracy corresponding to the uncertainty in the 
level of the source emissions [13].

To calculate the uncertainty of measuring the noise level in the industrial zone, it is necessary to estimate the uncertainty of the measurement conditions. Thus, the determinations are made

$$
u_{(\text {sou })}=\sqrt{\sum_{1}^{n} \frac{\left(L_{m i} \bar{L}_{m)}^{2}\right.}{n-1}}
$$

where $L_{m i}$ is the measured value representing a typical cycle of operation, expressed in decibels (dB), $\bar{L}_{m}$ is the arithmetic mean of all $L_{m i}$, expressed in decibels (dB), and $n$ is the total

$$
u_{L}=\sqrt{c_{L}^{2} u_{L}^{2}+c_{\text {res }}^{2} u_{\text {res }}^{2}}
$$

where: $c_{L}$ is the sensitivity coefficient calculated for the measured noise level to be

$$
c_{L^{p}}=\frac{1}{1-10^{-0,1}\left(L^{\prime}-L_{\text {Tes }}\right)}
$$

$c_{\text {res }}-$ is the sensitivity coefficient calculated for the measured size of the residual noise to be

$$
c_{\text {res }}=\frac{-10^{\left.-0,19 L^{2}-L_{\text {res }}\right)}}{1-10^{-0,1}\left(L^{2}-L_{\text {res }}\right)}
$$

The uncertainty calculation also involves determinations of the residual noise level, measurements made at a distance large enough to eliminate or undetected the noise emitted by the tested sources [16].

For the noise level determined in the area with

$$
u_{\text {sou }}=\frac{c}{\sqrt{n}}
$$

where $n$ is the number of vehicles;

$\mathrm{C}=10$ for combined traffic as is the case with this study.

In this paper are presented the results of tests on the evaluation of the level of noise and chemical air pollution in two distinct urban areas: an industrial area and an area characterized by heavy road traffic, with a focus at distances small enough from the sources so that the variations in the sound pressure level are independent of the meteorological parameters according to equation 2 :

number of all independent measurements.

The total uncertainty is given by the following equation:

determined by the equation:

determined with the equation:

heavy traffic, the equivalent leq noise level is determined by the direct counting of all vehicles (regardless of their type) passing through the vicinity of the measuring point. The number of vehicles allows the calculation of standard uncertainty:

\section{EXPERIMENTAL PART}

\section{Location}

Figure 1 shows the two areas studied and the points at which the measurements were made. It should be added that for noise measurements and acoustic map making, a higher number of

on the novelty elements introduced by the regulations in force on the measurement and management of ambient and industrial noise levels by periodically developing specific noise maps. measuring points were made both near the main sources and at two distances of $50 \mathrm{~m}$ each as required by the noise mapping program. 


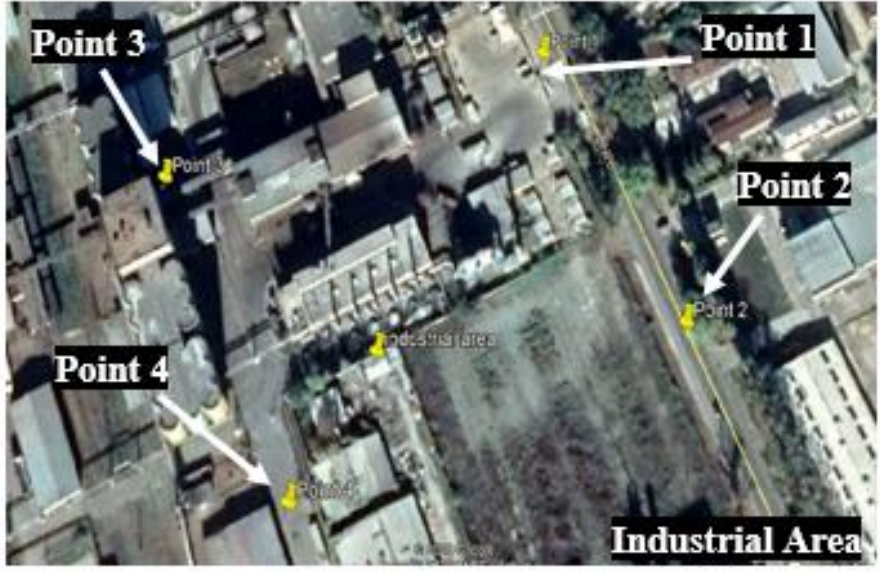

a)

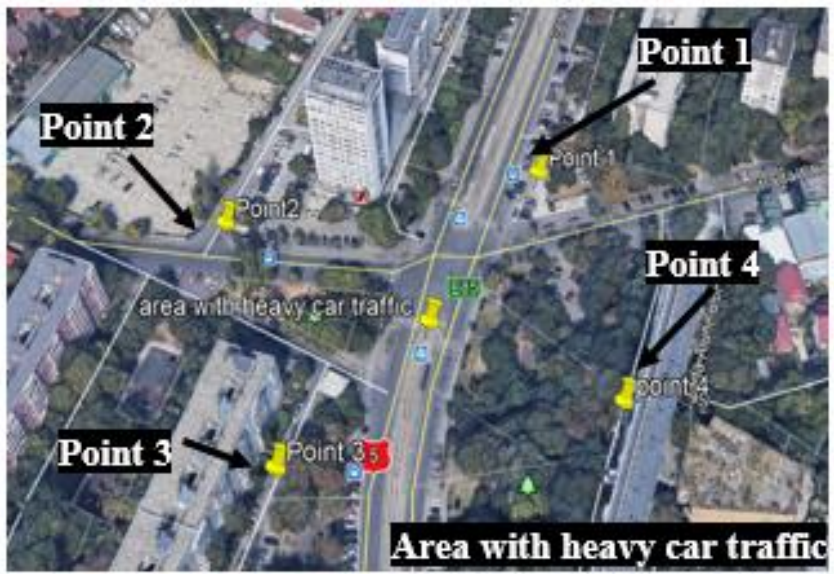

b)

Fig. 1. Areas studied on noise level and concentration of pollutants in emissions (a) industrial noise zone; b) area with heavy road traffic (road intersection)

\section{Methods and equipment}

The measurement of the noise level was carried out in compliance with the requirements of the method standard [16-18]: weather conditions for optimal measurements (stable meteorological conditions), calibrated measuring equipment before their use; thus, the meteorological parameters at the time of measurements were: ambient temperature $26^{\circ} \mathrm{C}$, atmospheric pressure 1004 mbar; relative humidity 32\%; wind speed $1.2 \mathrm{~m} / \mathrm{s}$, wind direction NE, nebulosity: clear skies. The noise level measurements for the industrial zone were carried out under operating conditions of the noise emission sources at maximum parameters. For pollutants determined at the emissions, 4 measuring points were established and the determinations were made under the standards of the method in force [19-21]. For the measurement of $\mathrm{NO}_{2}, \mathrm{SO}_{2}$, and $\mathrm{CO}$ at the emissions, the measuring equipment was placed

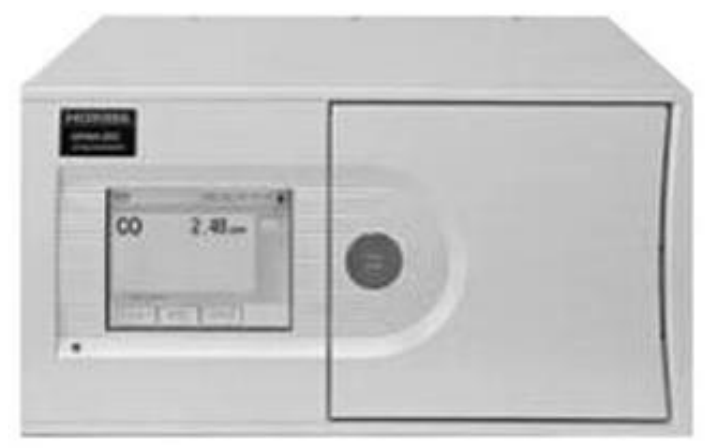

a) in the points shown in Figure 1 as follows: for the industrial zone at the limit of industrial property and the area with heavy road traffic (intersection) two points near the street and the other two at a distance of about $50 \mathrm{~m}$ from the street in the area with vegetation. The tests were carried out at a maximum activity time interval for the areas studied. Figure 2 shows the equipment with which the measurements were carried out: for pollutants in the surrounding air $\mathrm{CO}, \mathrm{NO}_{2}$ si $\mathrm{SO}_{2}$ - automatic analyzers Horiba (Fig. 2a), which perform continuous measurements by the following methods: spectrometry in IR non-dispersive for $\mathrm{CO}$, fluorescent for $\mathrm{SO}_{2}$ and chemiluminescence for $\mathrm{NO}_{2}$; for the noise level was used Sonometer Light Brüel \& Kjaer 2250 (Fig. 2b) provided with class 1 calibrator CAL 21 SOUND CALIBRATOR.

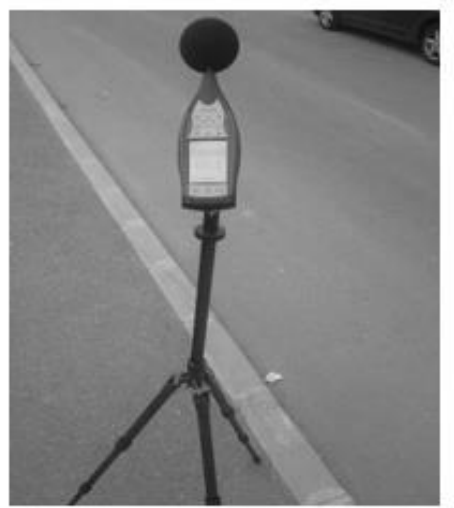

b)

Fig. 2. Equipment for measurements (a) and noise level (b) 
Noise level measurements were made over 10 minutes for each point and results were made to measurements representing the noise level in $(\mathrm{dB})$ over the frequency range between $31.5 \mathrm{~Hz}$ and $8 \mathrm{kHz}$ was used to make the noise map for the two areas studied. The values obtained were compared with the limits presented in the current legislation: SR 10009:2017 for the noise level, for the pollutants measured at the

\section{RESULTS AND DISCUSSION}

Figure 3 shows graphically the values determined for the noise level in the industrial zone (Fig. 1a) and in Figure 4 the values of the emissions: $\mathrm{NO}_{2}$ si $\mathrm{SO}_{2}$ (1-hour measurements) Law 104/2011; CO (30-minutes measurements) - STAS 12574-87 [22-24].

The results of noise measurements were used to make noise maps for both sites. For noise level mapping, the software was used as a software PREDICTOR 7810 Version 6.1 from Brüel \& Kjaer.

noise level measured at the points established for the characterization of noise pollution in the urban area with heavy road traffic (Fig. 1b).
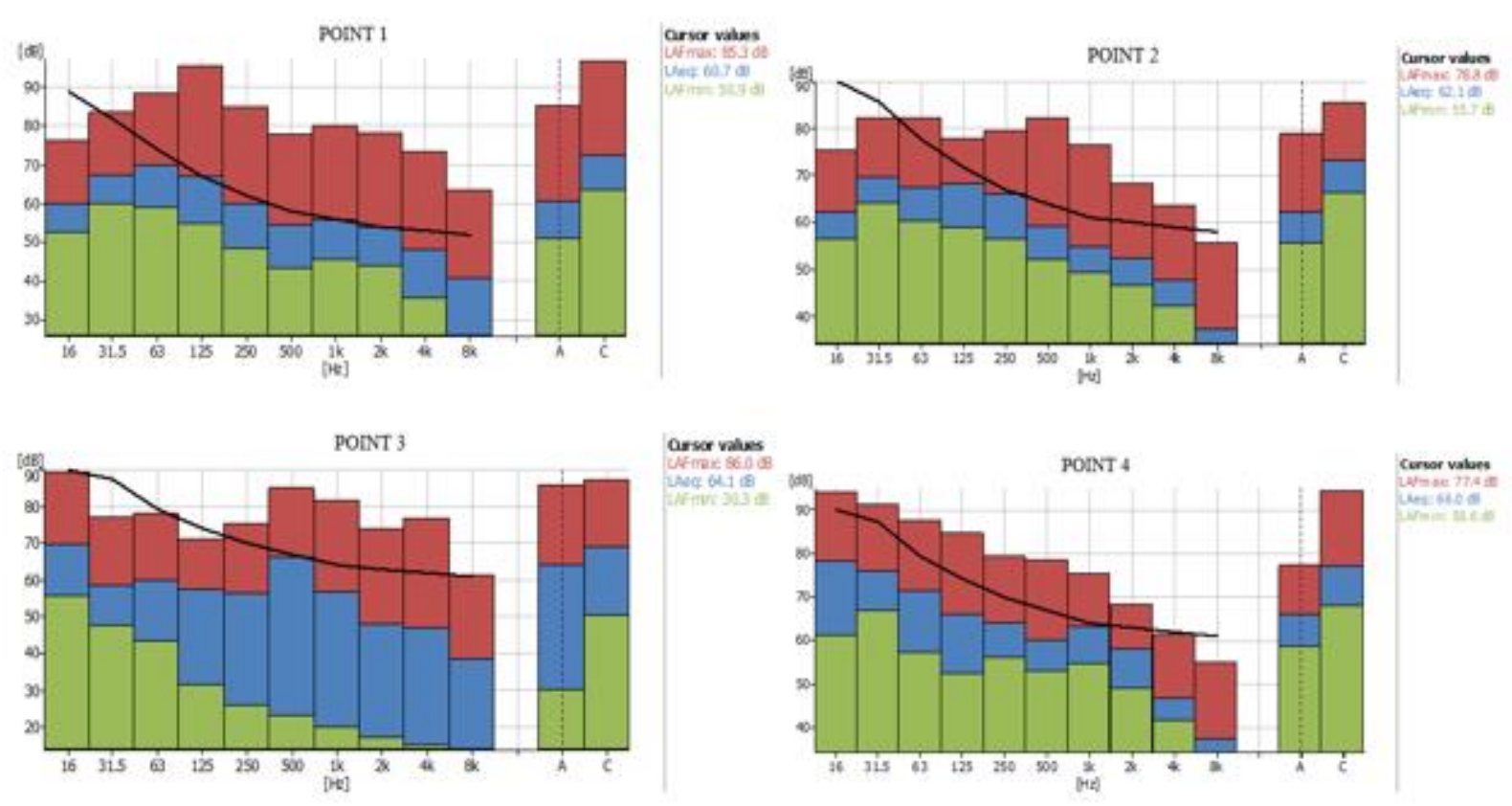

Fig. 3. Noise measurement graphs depending on the frequency at the 4 points

It is found that the values recorded in these points are: Point $1-60.7 \mathrm{~dB}$; Point $2-62.1 \mathrm{~dB}$; Point 3 - 64.1; Point $4-65.1$. Note that these values are not corrected according to residual noise.

Measurements were made for residual noise to calculate the measurement uncertainty $\mathrm{U}(\mathrm{k}=2)$

$$
L=10 \lg \left(10^{L /} / 10-10^{L_{\text {res }} / 10}\right)
$$

After making corrections for the noise level measured according to the residual noise, values for the measured noise level between 59.2-63.8 resulting in values between $\pm 4.2 \div \pm 4$. 8 , as well as for making corrections depending on the measured noise level. Thus, because the difference between the measured and residual noise level is greater than $3 \mathrm{~dB}$, corrections were required using the equation:

$\mathrm{dB}$ values that fall within the limits stipulated in the legislation. 

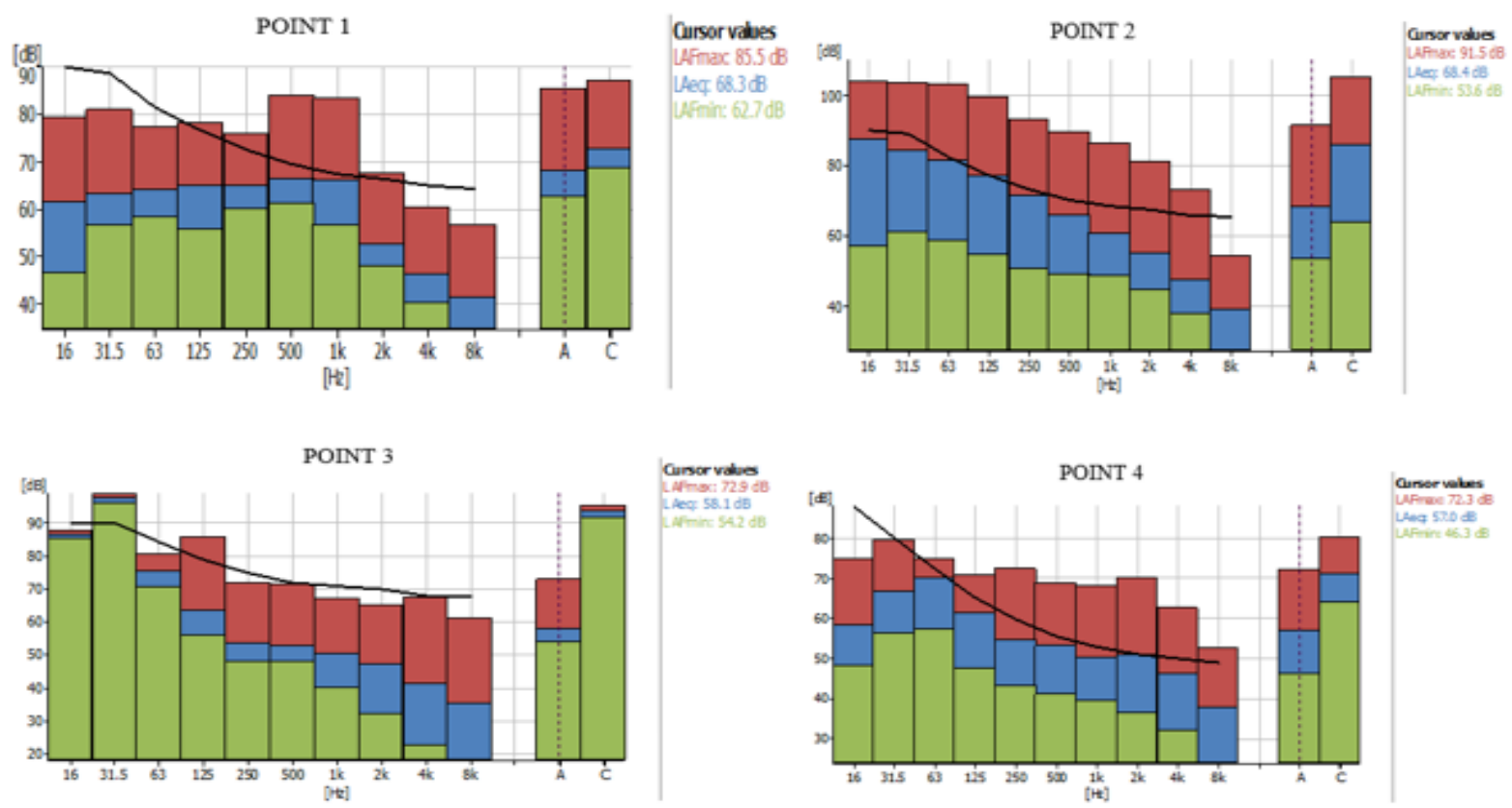

Fig. 4. Noise measurement graphs depending on the frequency at the 4 points

For the second area studied, noise levels between $55-62$. The limit for the street of technical category II, the link is $70 \mathrm{~dB}$ and the value limit for the noise level near the dwelling is $50 \mathrm{~dB}$ [22]. The values recorded for the noise level are: Point $1-68.3 \mathrm{~dB}$; Point $2-68.4 \mathrm{~dB}$; Point $3-58.1 \mathrm{~dB}$; Point $4-57.0 \mathrm{~dB}$. And in this case, measurements were made for the residual noise both to calculate the measurement uncertainty $U(\mathrm{k}=2)$ resulting in values between $\pm 4.6 \div \pm 5.2$, as well as for making corrections depending on the measured Figure 5 shows the noise map for the industrial area and Figure 6 shows the values calculated noise level. After making the corrections, the noise level values became: Point $1-67.9 \mathrm{~dB}$, Point 2-68.1 dB ; Point 3-55.8 dB; Point $4-$ $54.9 \mathrm{~dB}$. The conditions in which the measurements were performed, the peak period of the urban traffic, determined the obtaining of more values for points 1 and 2 because the measurements were performed near the street and points 3 and 4 are lower values that slightly exceed the limit. from the legislation for values of the noise level near the house.

by the noise map software used, values of the noise level at the edge of the studied area.
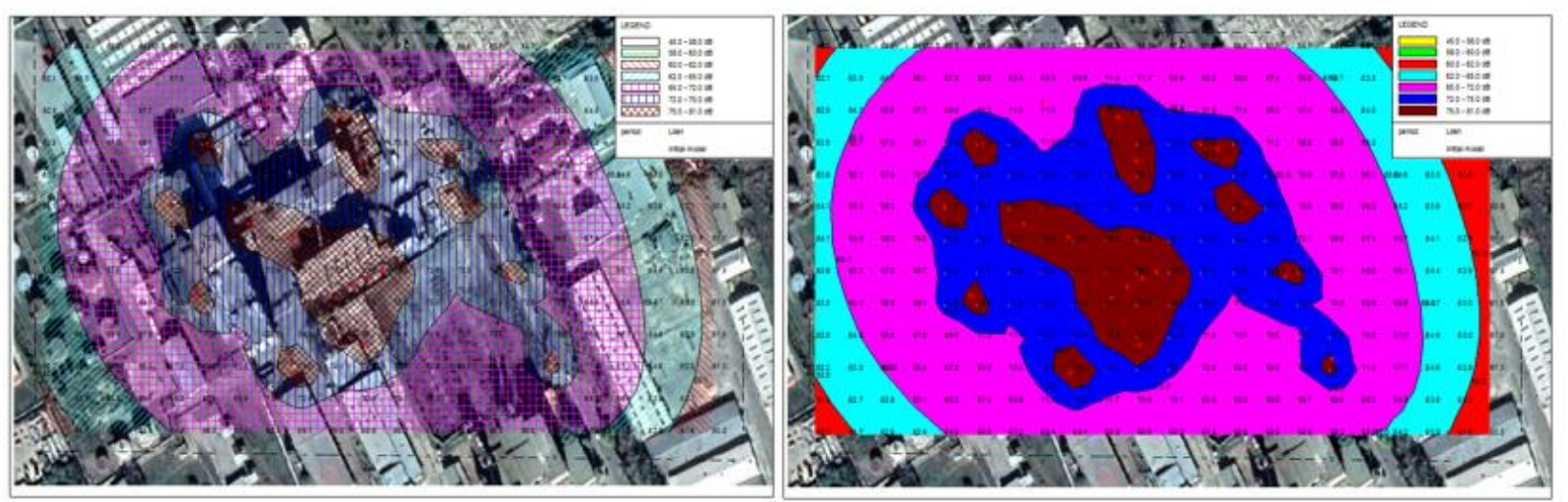

Fig. 5. Map regarding the dispersion of sound waves for the industrial area

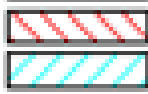

a)
$600-1000$ $620-406$

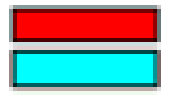

b)
$600-62006$ $620-65006$

Fig. 6. Noise level values recorded at the edge of the industrial area

(a) hatched figure; b) colored figure 
Thus, it is observed that at the edges of the studied area, the noise level reaches values between $60-65 \mathrm{~dB}$. The limit for industrial premises and spaces with activities assimilated to industrial activities is $65 \mathrm{~dB}$ thus, the values at the limit of the studied area fall within the limits provided in the legislation [22].

For the area with heavy road traffic, Figure 7 shows the noise map and Figure 8 shows the values calculated by the noise map software used, values of the noise level at the edge of the studied area.
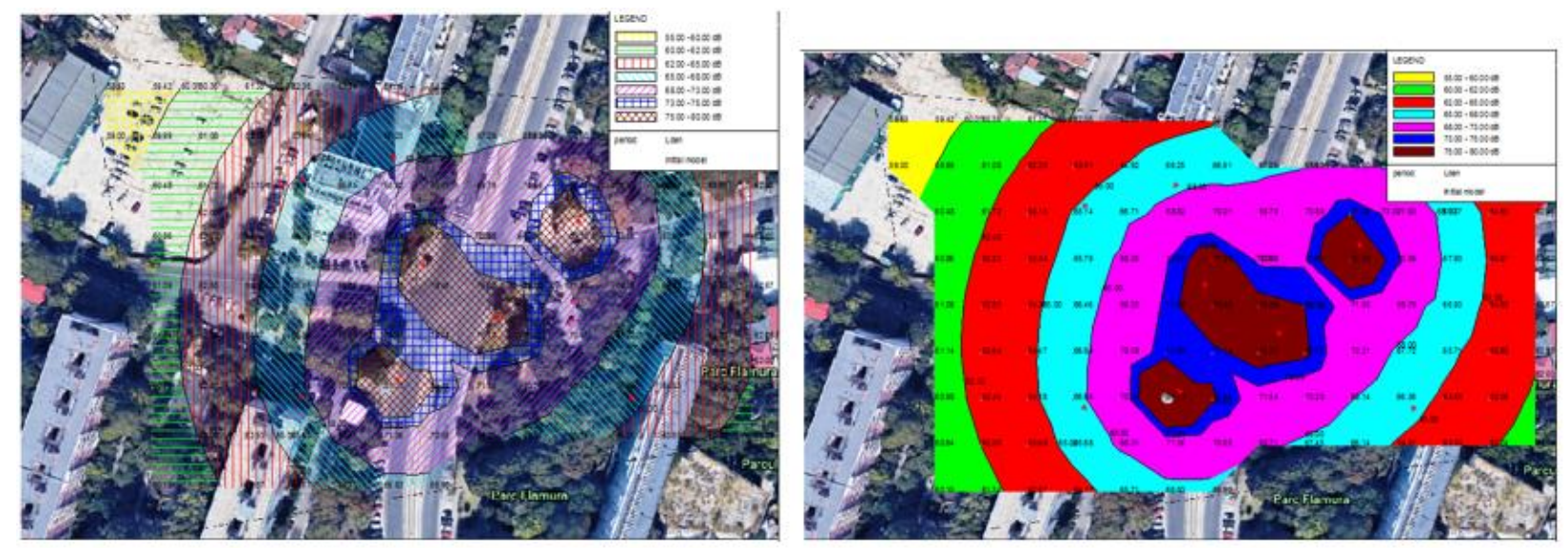

Fig. 7. Map regarding the dispersion of sound waves for the area with heavy road traffic

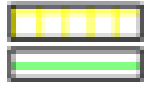

a)

) $\operatorname{sen} 4000 \mathrm{de}$ $6900-5200$ de

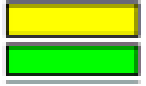

$5500-6000 d 8$

$6000-6200 d 8$

b)

Fig. 8. The recorded values of the noise level at the edge of the area with heavy road traffic

a) hatched figure; b) colored figure
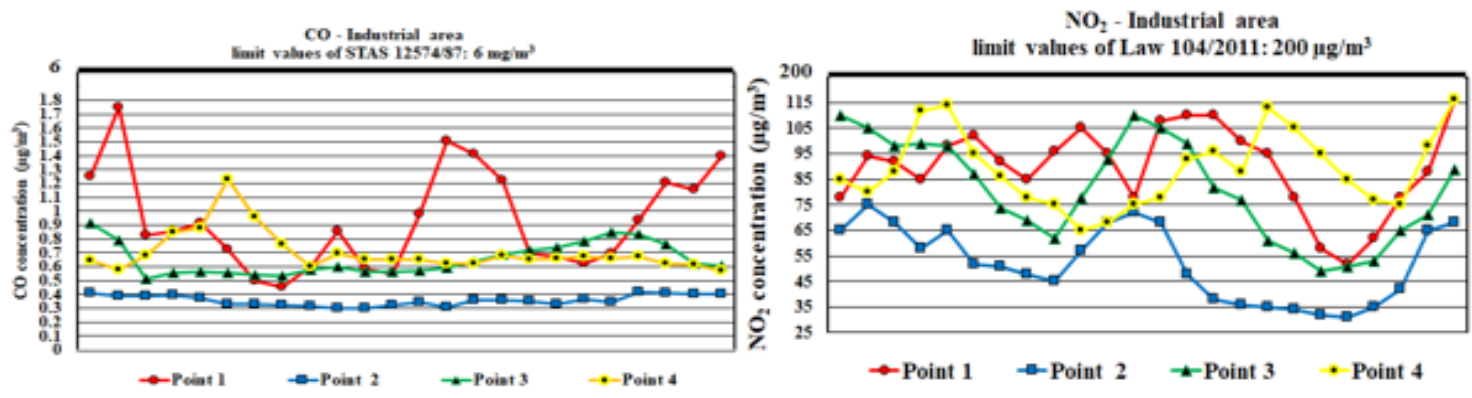

$\mathrm{SO}_{2}$ - Industrial area

limit values of Law 104/2011: $350 \mu \mathrm{g} / \mathrm{m}^{3}$

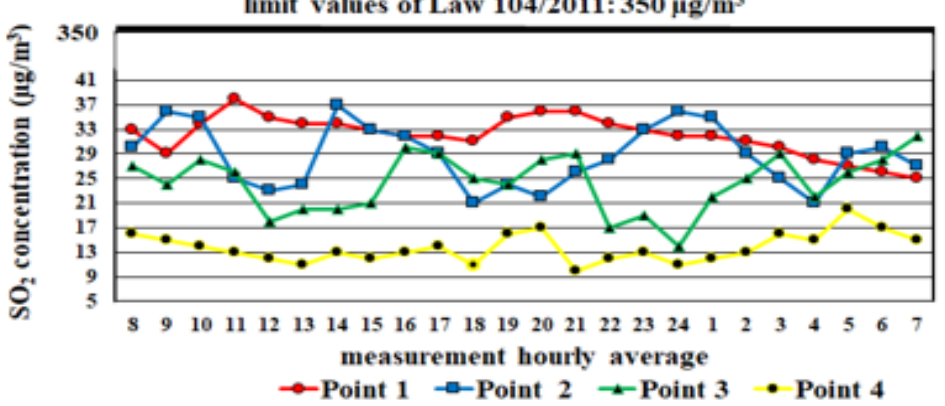

Fig. 9. Graphs of $\mathrm{CO}, \mathrm{NO}_{2}$, and $\mathrm{SO}_{2}$ measurements in the industrial area

For the pollutants determined at the immissions, their concentrations and the evolution in time are presented in Figure 9 for the industrial area and 10 for the urban area.
According to in force legislation, the limits for these pollutants are: $\mathrm{CO}-6 \mathrm{mg} / \mathrm{m}^{3}(30 \mathrm{~min})$; $\mathrm{NO}_{2}-200 \mu \mathrm{g} / \mathrm{m}^{3}$ (1 hour); $\mathrm{SO}_{2} 350 \mu \mathrm{g} / \mathrm{m}^{3}(1$ hour). As can be seen from Figure 9, these 
pollutants do not exceed the limits provided by law. A maximum value of $1,8 \mathrm{mg} / \mathrm{m}^{3}$ has been reached at point 1 and the lowest $\mathrm{CO}$ concentration was recorded at point 4 . This is explained by the direction of the $\mathrm{NE}$ wind towards point 1. Anyway, on point 1 the highest values were observed for $\mathrm{NO}_{2}(115$ $\left.\mu \mathrm{g} / \mathrm{m}^{3}\right)$ and $\mathrm{SO}_{2}\left(38 \mu \mathrm{g} / \mathrm{m}^{3}\right)$.
Higher values are observed for the pollutants determined at immissions for the second case, especially at points 1 and 2 located near the street where the noise level is also higher (Fig. 10). Points 3 and 4 show lower values for both $\mathrm{NO}_{2}, \mathrm{SO}_{2}$, and $\mathrm{CO}$ pollutants and the noise level due to the attenuation caused by the vegetation curtain.
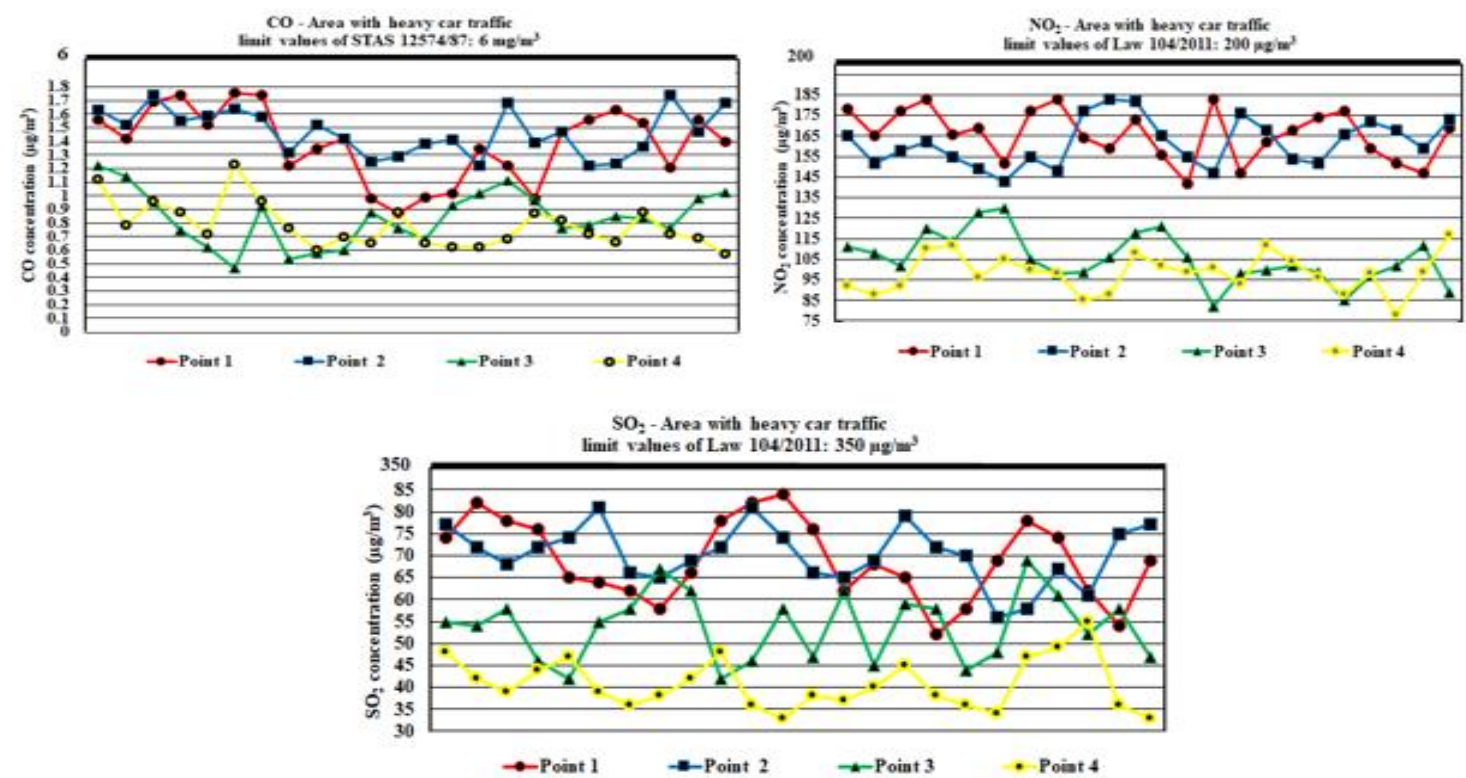

Fig. 10. Graphs of $\mathrm{CO}, \mathrm{NO}_{2}$, and $\mathrm{SO}_{2}$ measurements in the area with heavy road traffic

\section{CONCLUSIONS}

The results of tests performed to assess the level of noise and chemical pollution with $\mathrm{CO}, \mathrm{NO}_{2}$, and $\mathrm{SO}_{2}$ highlight the following aspects:

In the case of the industrial area, points 3 and 4 present higher values for the noise level 64.1 $\mathrm{dB}, 65.1 \mathrm{~dB}$ because it is in the vicinity of noise sources (industrial fans). From air pollution, higher concentrations were obtained in point 1 , located in the wind direction, values that fall within the limits imposed by the legislation.

In the case of the studied urban area with heavy road traffic, higher values were obtained both for the noise level and the chemical pollutants in points 1 and 2 points that are placed near the

\section{ACKNOWLEDGEMENTS}

The tests were carried out in the Competitiveness Operational Program project nr. 55/05.09.2016 "Promoting, identifying and implementing partnerships for the transfer of street. For the other measurement points, the values are lower due to the vegetation area that attenuates both the noise level and the concentration of $\mathrm{CO}, \mathrm{NO}_{2}$, and $\mathrm{SO}_{2}$ in the ambient air.

It is recommended in this situation to increase the areas with vegetation in urban areas to reduce both the noise level and the chemical pollution of the air with compounds specific to traffic emissions. For the industrial area, the placement of attenuators or sound-absorbing barriers in the vicinity of noise emitting sources will reduce the level of noise pollution in the workplace and in the vicinity of industrial units.

knowledge in the field of industrial ecology", ID_P_40_300, cod SMIS 105581, Subsidiary contract nr. 2142/12.02.2019. 


\section{REFERENCES}

[1] DANCIULESCU, V., BUCUR, E., PASCU, L. F., VASILE, A., BRATU, M., J. Environ, 16, no 3, 2015, p. 815.

[2] KARAKITSIOS, S.P., PAPALOUKAS, C.L., KASSOMENOS, P.A., PILIDIS, G. Ecol Modell, 193, no. 15, 2006, p. 253, https://doi.org/10.1016/j.ecolmodel.2005.07.02 4.

[3] LASLU, E. R., LASLU, G. M., Economic aspects of environmental protection, Publisher VOX, 2003, p. 73.

[4] SYGNA, K., AASVANG, G.M., AAMODT, G., OFTEDAL, B., KROG, N.H., Environ. Res. 131, 2014, p. 17, https://doi.org/10.1016/j.envres.2014.02.010.

[5] BEGOU, P., KASSOMENOS, P., KELESSIS, A., Sci. Total Environ., 703, 2020, https://doi.org/10.1016/j.scitotenv.2019.134477. [6] MUZET A., Sleep Med. Rev, 11, no. 2, 2007, p. 135.

[7] DRUG G., Noise pollution in Iasi factors discomfort and health risks exposed, Ph.D. Thesis, University of Medicine and Pharmacy “GR. T. POPA " IAȘI, 2011, p. 5-10.

[8] IASNICU I., VASILE O., IATAN R., TOMESCU G., JETR, 21, no 2, p. 48 https://doi.org/10.5897/JETR2020.0691.

[9] DARABONT, A., Modern means of combating noise and vibration, Central Institute of Technical Documentation, 1971, Bucharest.

[10] ENESCU, N., MAGHETI, I., SARBU, M.A., Acoustic technique, Ed. ICPE, 1998, Bucharest.

[11] VASILE, O., Acoustic technique Laboratory Guidebook, Ed. Politehnica Press, 2013 Bucharest.

[12] BRATU M., DUMITRESCU O., VASILE O., PASCU L. F., LEHR C., Rev. Rom. Mater., 48, no 4, 2018, p. 467.

[13] Directive (UE) 2002/49/CE of the European Parliament and of the Council of 25
June 2002 on the assessment and management of environmental noise, [Official Journal of the European Union].

[14] Directive (UE) 2015/996 a Commission of 19 May 2015 establishing common methods for the assessment of noise, [Official Journal of the European Union].

[15] Law 121/2019 on Ambient Noise Assessment and Management, Official Monitor part $1 \mathrm{nr} .604 / 2019$, [in Romanian].

[16] ISO 1996:2017 Acoustics. Description, measurement, and evaluation of ambient noise. Part 2: Determination of noise levels ambient.

[17] ISO 1996-1:2016 Acoustic. Description, measurement, and assessment of ambient noise. Part 1: Fundamental sizes and assessment methods.

[18] STAS 6161/3-82: Acoustics in construction. Determining the noise level in urban localities. Method of determination, www.asro.ro, [in Romanian].

[19] EN 14626:2012 Ambient air. Standardized method for measuring the concentration of carbon monoxide by non-dispersive infrared spectroscopy.

[20] EN 14212:2012 Ambient air - standard method for the measurement of the concentration of sulfur dioxide by ultraviolet fluorescence.

[21] EN 14211:2012 Ambient air. Standardized method for measuring the concentration of nitrogen dioxide and nitrogen monoxide by chemiluminescence.

[22] SR 10009:2017 Acoustics. Permissible limits of ambient noise level, www.asro.ro, [in Romanian].

[23] Law 104/2017: Ambient air quality, Official Monitor no. 452/2011, [in Romanian]. [24] STAS 12574 - 1987 Air from protected areas. Quality conditions, www.asro.ro, [in Romanian]. 